\title{
Comparison of the Efficacy of Ultrasonography with Computed Tomography in the Diagnosis of Maxillomandibular Fractures
}

\author{
Lekha Airan $^{1}$, Mohan Baliga ${ }^{2}$, Souvick Sarkar ${ }^{3}$, Subhagata Chakraborty $^{4}$, Dani M Tusharbhai ${ }^{5}$
}

\begin{abstract}
Background: Head and neck trauma forms a major proportion of patients requiring maxillofacial care. Imaging is a vital part in the management of these patients. Many modalities exist that maybe utilized for the purpose of visualizing the fracture defects. Computed tomography (CT) scans have been considered the gold standard even with many disadvantages like associated radiation hazards, high cost factor, unavailability in rural healthcare setup, and time taken for the scans.

Aim: Through our study, we aim to compare the efficacy of ultrasonography (USG) and compare it with CT scan in the detection of maxillomandibular fractures.

Materials and methods: Over a 2-year period, 50 patients suspected with zygomatico-complex (ZMC) or mandible fractures underwent clinical examination followed by radiographic assessment using ultrasound and CT scans. The sensitivity, specificity, and time taken to evaluate the fractures were determined and compared.

Results: High correlation existed between USG and CT scan in the detection of the maxillomandibular fractures. The sensitivity was $95 \%$ and the specificity was $90 \%$ with a high positive predictive value.

Conclusion: Apart from a few disadvantages like difficulty in interpretation of a film without a report or clinical correlation and examiner variability, the advantages associated with its use probably outweigh the shortcomings.

Keywords: CT scanning, Maxillofacial, Maxillomandibular trauma, Ultrasonography.

World Journal of Dentistry (2019): 10.5005/jp-journals-10015-1632
\end{abstract}

\section{INTRODUCTION}

Trauma is the major cause of morbidity and mortality worldwide, especially in developing nations, and is the leading cause of death among young individuals under the age of $45 .{ }^{1}$ Maxillofacial injuries, such as mandibular and zygomatic complex fractures, are commonly encountered either as polytrauma patient or isolated fractures as a result of direct trauma to the face. ${ }^{2}$ It has a fundamental role in facial esthetics and the normal functioning of the stomatognathic system. Therefore, it is essential that maxillofacial injuries are appropriately diagnosed and treated. Management of traumatized victim involves a comprehensive history and initial examination, supplemented with appropriate radiographs based on the clinical presentation. Various imaging modalities are available ranging from the simplest plain film radiographs that have proven to have certain shortcomings, USG, to CT, which is now considered as the "gold standard."

USG is a rapid, dynamic, noninvasive, and inexpensive radiographic technique, recently considered in evaluating maxillofacial fractures, which can be considered as an alternative to CT scans. ${ }^{4}$

The present study highlights the prospect of radiation-free USG in comparison with CT scans in the diagnosis of the facial fracture of the midface including zygomatic complex/arch and mandible.

The objectives of the study are (i) to assess and compare the sensitivity and specificity of USG against CT scans in diagnosing fractures of midface, zygomatic complex, and mandible, and (ii) to evaluate and compare the time taken for the complete scanning and processing of USG and CT scans.

\begin{abstract}
${ }^{1-5}$ Department of Oral and Maxillofacial Surgery, Manipal College of Dental Sciences, Manipal Academy of Higher Education, Mangaluru, Karnataka, India

Corresponding Author: Mohan Baliga, Department of Oral and Maxillofacial Surgery, Manipal College of Dental Sciences, Manipal Academy of Higher Education, Mangaluru, Karnataka, India, Phone: +91 9845543483, e-mail: mohan.baliga@manipal.edu

How to cite this article: Airan L, Baliga M, et al. Comparison of the Efficacy of Ultrasonography with Computed Tomography in the Diagnosis of Maxillomandibular Fractures. World J Dent 2019;10(3): 181-185.

Source of support: Department of Oral and Maxillofacial Surgery, MCODS Mangalore and Kasturba Medical College, Manipal Academy of Higher Education

Conflict of interest: None

\section{Materials and Methods}

A 2-year comparative study was carried out among the patients who reported with maxillofacial fractures, at the Department of Oral and Maxillofacial Surgery at MCODS hospital lighthouse/Attavar and casualty of KMC Attavar/Ambedkar circle. The ethical clearance was procured from the institutional ethics committee of Manipal College of Dental Sciences, Mangaluru, and the data collection progressed from 1 November 2015 to 1 November 2017. Informed consent was taken from all patients prior to data collection.
\end{abstract}

\section{Data collection}

Data was collected in three steps from each patient:

(-) The Author(s). 2019 Open Access This article is distributed under the terms of the Creative Commons Attribution 4.0International License (https://creativecommons. org/licenses/by-nc/4.0/), which permits unrestricted use, distribution, and non-commercial reproduction in any medium, provided you give appropriate credit to the original author(s) and the source, provide a link to the Creative Commons license, and indicate if changes were made. The Creative Commons Public Domain Dedication waiver (http://creativecommons.org/publicdomain/zero/1.0/) applies to the data made available in this article, unless otherwise stated. 
- Thorough history and physical examination of each patient was carried out by the principal investigator.

- The patients in whom an underlying fracture was suspected were referred for the radiographic assessment, subsequently, for imaging by CT and ultrasound for the diagnosis of the fracture.

- The radiologist was blinded to the CT findings if already present and was asked about the USG examination.

- Surgery was carried out as soon as the patient was considered fit to undergo surgical treatment under general anesthesia.

USG examinations were performed using the GE Wipro Voluson 730 Expert USG model with the SP6-2 H linear transducer probe with a frequency of 3.0-11 MHz or Philips Envisor Unit with an L12-3 linear transducer with a 3-12 MHz extended frequency range by a single experienced radiologist, blinded to the CT findings.

CT scanning unit used was the GE Hi speed DXI single slice scanner and the 16 slice MDCT GE Brivo 385 unit. The total time taken for the evaluation with USG was from application of the transducer to reporting of the USG, whereas the time taken for the CT scan was from the start of the exposure to printing the film.

Data from CT was compared with that of USG. The inclusion criteria for the patients were: (i) male or female participants of any age; and (ii) must have known or suspected fractures of the midface or mandible. The exclusion criteria were: (i) subjects with compromised airway and obvious head injuries; (ii) patients who were unwilling to give informed consent for the study; and (iii) immunocompromised individuals including those with severe debilitating diseases. A total of 50 patients, 35 males and 15 females, were included in the study.

\section{Results and Observation}

After reading the patient information sheet and signing the informed consent form, 50 patients who met the inclusion criteria formed the study sample of the present research. Of the patients included in the pool, 41 had maxillofacial fractures diagnosed by CT scan or USG, and 9 had no maxillofacial fractures. The most common cause for trauma was road traffic accidents followed by falls from height, interpersonal violence, and sports-related injuries. The pie chart (Fig. 1) shows the etiology of the trauma.

- The total time taken for the evaluation with USG starting from application of the transducer to reporting was in the range

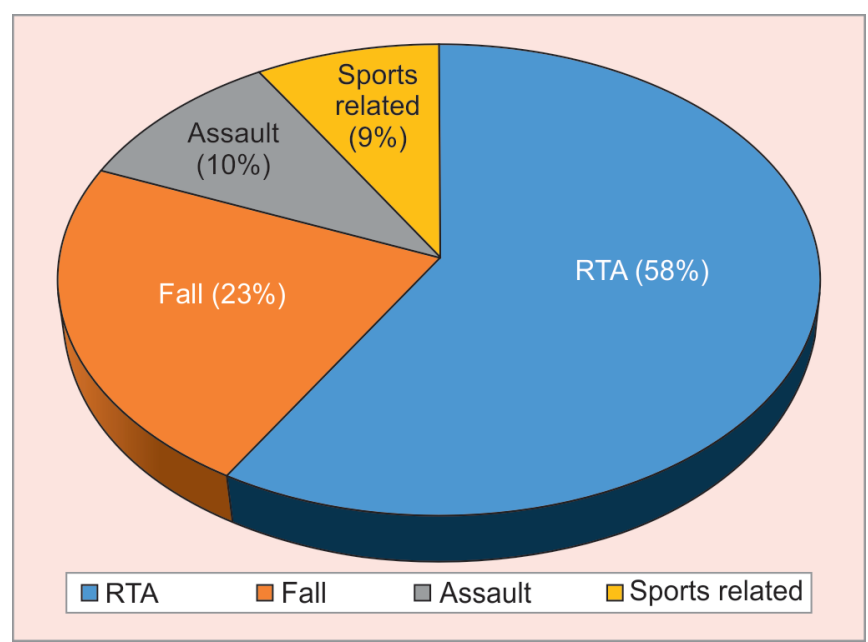

Fig. 1: Etiology of fracture of 5-12 minutes for all patients with the mean value being 8.5 minutes. Whereas the time taken for the CT scan from starting the exposure to printing the film took over 10-15 minutes, the average being 12.5 minutes.

- USG was able to identify the fracture in all except two patients, one at the angle of mandible and the other at the posterolateral wall of the maxillary sinus. CT scan was able to identify all the fractures in all the patients, but certain fractures required reformatted coronal and sagittal images. These fractures were found to be undisplaced. Reconstructed 3D images were not very precise and reliable. However, in one case a suture line was misdiagnosed as fracture in USG, which was later ruled out in CT scan.

- When a conventional radiograph was made, the identification of the fracture sites was often difficult to interpret as it relied heavily on the technician's skill and the inherent shortcomings in the projection geometry.

\section{Discussion}

The incidence, demographics, and epidemiological factors of maxillofacial trauma vary extensively across different parts of the world due to multiple factors, such as socioeconomic, cultural, traffic rules and regulations, and laws prohibiting drunken driving. ${ }^{5}$

These injuries can not only be life-threatening, given the possibility of extensive immediate hemorrhage and airway compromise, but often result in facial disfigurement, loss of function of stomatognathic system, and the most severe form can lead to blindness.

The systematic management of these injuries has remained constant over the years and includes a quick but thorough history, detailed physical examination as per the advanced trauma life support (ATLS) protocol for managing the traumatized victim followed by scanning of the respective regions where injuries are suspected. ${ }^{6}$

Imaging forms the backbone in the emergency medical and surgical management of the patients in the emergency department. The most commonly employed diagnostic tools for screening for trauma to the head and neck region include conventional plain film radiographs, orthopantomography, CT scans, and the recently introduced cone beam CT.

Ever since the introduction of X-ray, these ionizing forms of radiographs had been the norm. However, in the recent times, with the principle of as low as reasonably achievable (ALARA) gaining importance in the moral and ethical treatment of the patient, it has become redundant to practice these traditional radiological diagnostics because of hazards associated with radiation exposure, such as developments of cataracts and radiation injuries. ${ }^{7}$

Introduction of ultrasounds into the world of medical practice was done by Dr Donald during World War II. ${ }^{8}$ It is an indispensable tool in the field of radiodiagnosis as a noninvasive, inexpensive technique that offers an advantage over other traditional radiographic modalities by eliminating the harmful biological side effects of X-ray production.

There are a considerable number of merits that provide USG as a radiodiagnostic modality an edge over other techniques. Ultrasound facilities are readily available and are little dependent on patient cooperation. The technical sensitivity of the patient positioning is minimal, and it is also a dynamic procedure that may be performed in real time by an experienced radiologist. The equipment is compact and portable enough to be transported 
either into emergency room, rapid bedside imaging, or even into operating theater for intraoperative evaluation. There are no biological risks associated with its use, so it can be repeated multiple times. $^{4}$

As described in our study, sonography has the scope and potential to be employed efficiently in the primary care of trauma patients. Its application to the musculoskeletal system has been identified only recently. It can now be considered as an alternative to conventional radiographs to rule out trauma, as first-line imaging, or as adjunct to $C T$.

USG has shown very high accuracy for the detection of nasal bone fractures with the sensitivity ranging from 90 to $100 \%$, specificity of $98-100 \%$, and high predictive values. ${ }^{9,10}$ These findings were supported by the reports of Friedrich et al. ${ }^{11}$ and Hirai et al., ${ }^{12}$ thus establishing that USG is an adequate investigation for clinically suspected isolated nasal bone fractures.

In our study, we observed a significant positive agreement between the USG and the CT scans in the diagnosis of mandibular and ZMC fractures. We have taken CT scans to be the gold standard and aimed to prove USG to be equally effective in diagnosing mandibular and middle third fractures, and we obtained a sensitivity of $95 \%$, a specificity of $90 \%$, and a positive predictive value of $97.44 \%$. The interpretation is calculated and interpreted in Tables 1 and 2. Based on the key article by Singh, the sensitivity of the USG technique is represented as $97.4 \% .^{13}$ Assuming a difference in the sensitivity of $5 \%$, we need a sample of 41 to arrive at a conclusion based on the formula $N=\frac{Z^{2} S e(1-S e)}{d^{2} \times \text { Prev }}$. We took a sample of 50 for our study as the minimum requirement was 41 .

The results obtained indicate a strong and significant correlation between CT and USG for the diagnosis of fractures. Figures 2 and 3 depict fracture of the mandible; Figure 4 depicts fracture of midface ultrasonographically; and it can be compared to those fractures in CT scan in Figures 5 and 6.

Step-like, displaced fractures were easier to diagnose when compared to minimally displaced fractures and nondisplaced fractures. In our study, we had two undisplaced fractures that could

Table 1: Calculation and statistical interpretation on the basis of USG

\begin{tabular}{lll}
\hline USG result & Positive & Negative \\
\hline+ & 38 (true positive $=\mathrm{a})$ & 1 (false positive $=\mathrm{c})$ \\
- & $2($ false negative $=\mathrm{b})$ & $9($ true negative $=\mathrm{d})$ \\
\hline
\end{tabular}

Table 2: Calculation and statistical interpretation of the study

\begin{tabular}{llll}
\hline Statistic & Formula & Value & $95 \% \mathrm{Cl}$ \\
\hline Sensitivity & $a / a+b$ & $95.00 \%$ & $83.08-99.39$ \\
$\begin{array}{l}\text { Specificity } \\
d / c+d\end{array}$ & $90.00 \%$ & $55.50-99.75$ \\
$\begin{array}{l}\text { Positive likeli- } \\
\text { hood ratio }\end{array}$ & $\begin{array}{l}\text { Sensitivity } / 1- \\
\text { specificity }\end{array}$ & 9.50 & $1.48-61.07$ \\
$\begin{array}{l}\text { Negative likeli- } \\
\text { hood ratio }\end{array}$ & $\begin{array}{l}1-\text { sensitivity/ } \\
\text { specificity }\end{array}$ & 0.06 & $0.01-0.22$ \\
$\begin{array}{l}\text { Disease preva- } \\
a+b / a+b+\end{array}$ & $80.00 \%\left(^{*}\right)$ & $66.28-89.97$ \\
$\begin{array}{l}\text { lence } \\
\begin{array}{l}\text { Positive predic- } \\
\text { tive value }\end{array}\end{array}$ & $a / a+c$ & $97.44 \%\left(^{*}\right)$ & $85.53-99.59$ \\
$\begin{array}{l}\text { Negative pre- } \\
\text { dictive value }\end{array}$ & $d / b+d$ & $81.82 \%\left(^{*}\right)$ & $53.43-94.64$ \\
Accuracy & $\begin{array}{l}a+d / a+b+ \\
\end{array}$ & $94.00 \%\left(^{*}\right)$ & $83.45-98.75$ \\
\hline
\end{tabular}

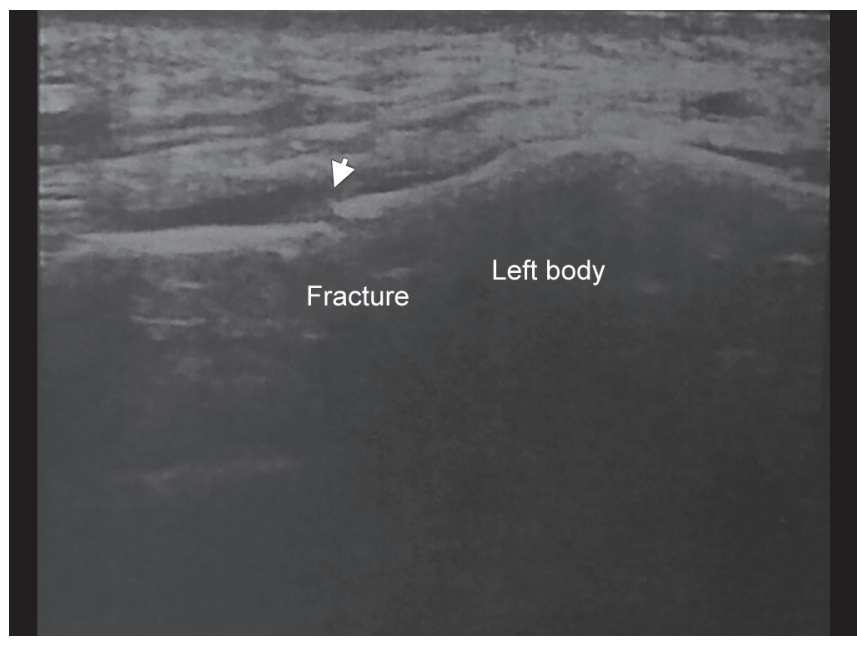

Fig. 2: USG showing fracture of left body of the mandible

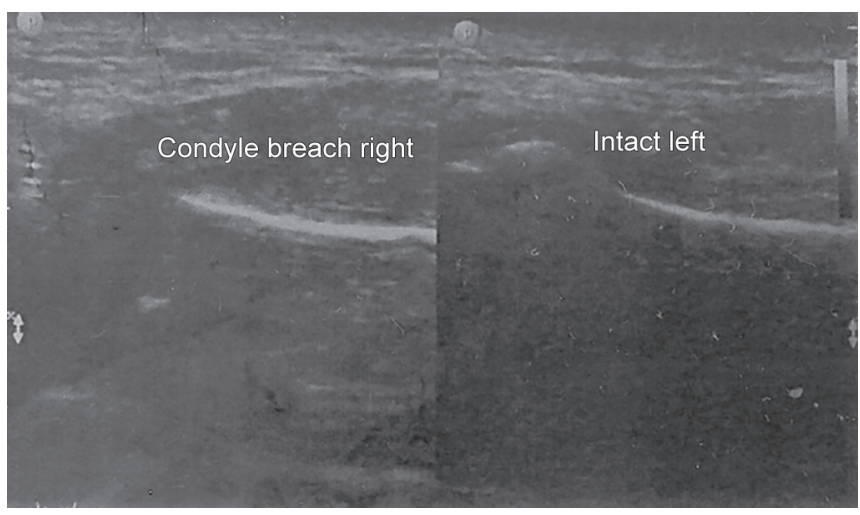

Fig. 3: USG showing fracture of left condyle

not be identified by USG. Even a 0.2-mm disruption in the fracture site could be identified in our study as agreed by Singh et al. $^{13}$ The accuracy of our study was assessed to be $94 \%$.

Very few authors have investigated the use of ultrasound in mandibular fractures. This is probably because mandibular fractures are easily diagnosed by clinical examination alone or with simpler conventional radiography like the orthopantomograph (OPG) or occlusal radiograph. Hirai et al. ${ }^{12}$ in their case series

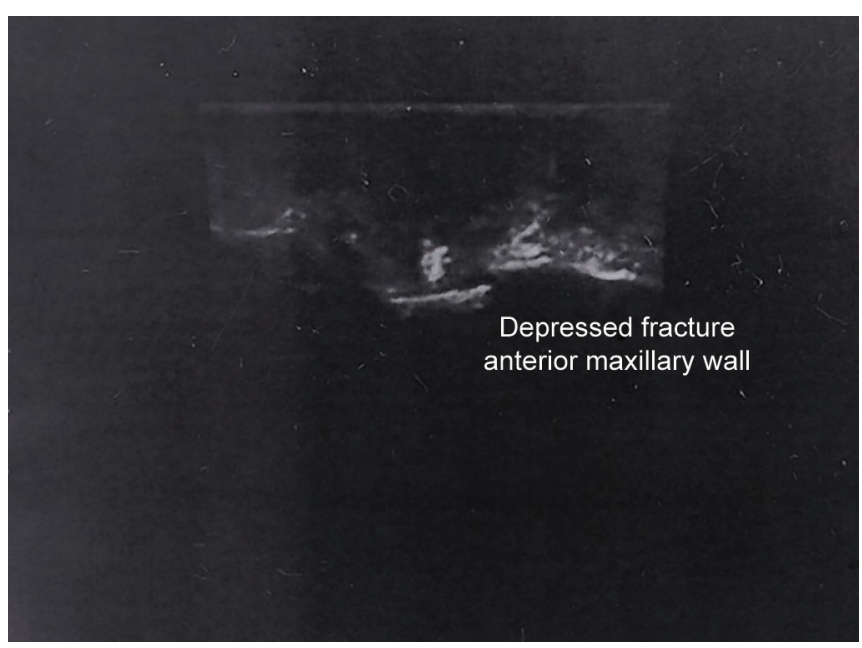

Fig. 4: USG showing depressed anterior maxillary wall fracture 

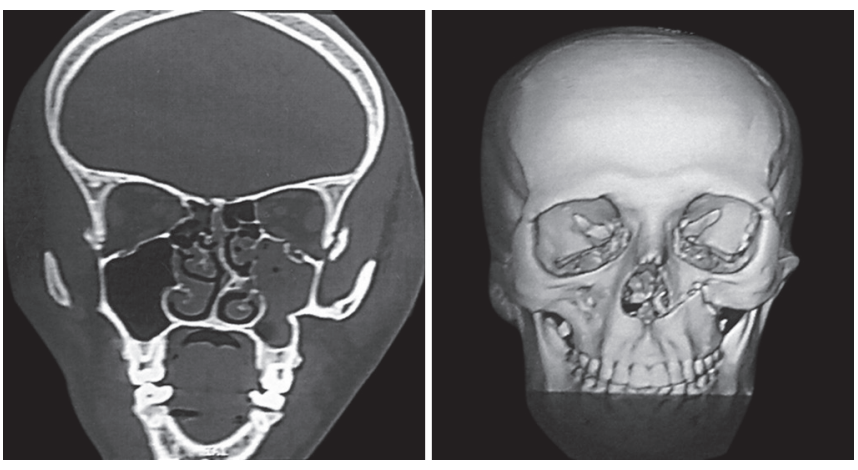

Fig. 5: CT axial image showing orbital floor fracture

demonstrated that USG could readily detect fractures of the mandibular symphysis and angle.

Kleinheinz et al. ${ }^{14}$ and Friedrich et al. reported USG sensitivity and specificity of $100 \%$ and $66 \%$, respectively; and Friedrich et al. ${ }^{11}$ reported USG sensitivity and specificity of $100 \%$ and $52 \%$, respectively, in the detection of mandibular subcondylar/ramus fractures.

In the emergency department, time plays the most crucial role. Keeping this in mind, we included the time taken for the investigation to detect fracture in our present study. Not many studies have compared this in the past. We observed that USG, apart from being portable and inexpensive, also readily detected the presence of a fracture. Whereas the time taken to shift the patient to the $\mathrm{CT}$ room, positioning on the gantry, setting the parameters, and loading data into the computer was a lengthier and slightly more cumbersome process.

Although, the ongoing research and their results are promising, further investigation is mandated to document strong evidence on the appropriateness of diagnostic USG in mandibular fractures.

The major disadvantage of the use of USG in the diagnosis of facial fractures lies in its inherent inability to identify undisplaced fractures ${ }^{15}$ or to differentiate the fracture from a suture line. Without a degree of displacement, there is a probability that the fracture may not be detected. Another drawback is that USG doesn't allow the fractured site in the craniofacial skeleton, although picked up, to be related to any adjacent anatomical landmark. In the absence of a report, the printed film alone will not be of much use. Clinical correlation is a must for the proper application of this tool to the diagnosis of the fracture.

Within the limitation of the design of this study, USG has proved to be a valid tool for the diagnosis of fractures of midface including zygomatic complex/arch, anterior wall of maxilla, nasal bone, displaced infraorbital margin, and mandibular fractures. It will be of prime importance in the coming future to explore and extend its validity in the diagnosis of undisplaced fractures and the use of smaller transducer probes to identify the specifications of the optimal probe size required that will aid in the diagnosis of nondisplaced fractures as well. ${ }^{15}$ We identify USG as being in its budding stage at present, in its application to the musculoskeletal system. A possible paradigm shift is likely to thrust it into higher places with more and more research and technical advancements occurring rapidly, and as radiologists gain proper training and greater experience in its potential application to the maxillofacial trauma setting.

The study hypothesizes the fact that USG can be used as an adjunctive tool to $\mathrm{CT}$ in the diagnosis of facial fractures. Through our results, we can conclude that its accuracy in diagnosing the
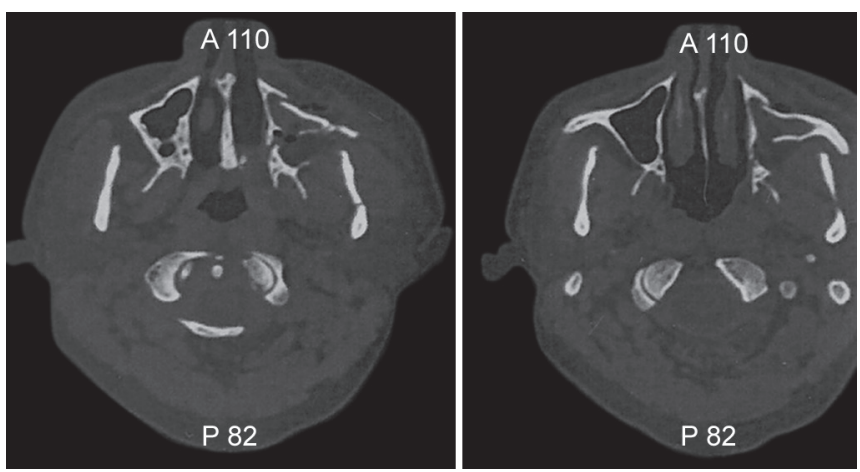

Fig. 6: CT scan showing left ZMC fracture

fractures is pretty good. So, in certain scenarios where the facility of CT scan is unavailable, we can still diagnose the patients with USG to a great extent and probably take them in for surgical intervention. There is no doubt that CT scan is the gold standard of diagnosis of maxillomandibular fractures, but USG surely can be an adjunct.

\section{Conclusion}

As rapid advancement in every field of the healthcare industry is occurring at a breakneck speed, it is essential to explore options that are more versatile and beneficial to both the patient and clinician in the field of maxillofacial traumatology as well. Ongoing research is encouraging, and the future is likely to witness many more clinicians opting to utilize this modality as the primary or perhaps even a definitive screening tool for the diagnosis of maxillofacial fractures without an underlying intracranial injury.

In our study, we observed the versatility and efficacy of this radiographic tool and keeping in mind, both the advantages and shortcomings, we realized that the use of USG is beneficial to the patient. It is advantageous to the patient because it is radiationfree, noninvasive, and can be helpful even for the uncooperative, restless patients, such as pediatric age group, or it can be used when ionizing radiation is contraindicated, such as in pregnant patients.

The full potential of USG is still undiscovered, and it calls for further exploration by radiologists and surgeons. From the technical point of view, the advances in the hardware technology and biophysics are dynamic and unending. Undoubtedly, this will lead to scaling of greater heights in the manufacturing of the ultrasonic scanning units and specifications of the probes. All the factors combined might witness this tool to eventually be considered a forerunner in the list of diagnostic modalities available for evaluation of fractures in the human skeleton.

\section{Clinical Significance}

Further research in the technical aspects and training in the application of this method in trauma management in near future is likely to witness USG becoming the modality of choice as an initial screening tool for detection of fractures.

\section{References}

1. Ballantyne B, Ling A, et al. The current role of focused assessment with sonography for trauma (FAST) in the ever-evolving approach to abdominal trauma. Univ West Ont Med J 2012;81:20-22.

2. Kumar GBA, Dhupar V, et al. Patterns of maxillofacial fractures in goa. J.Maxillofac Oral Surg. 2015 Jun;14(2):138-141. DOI: 10.1007/s12663013-0583-7. 
3. Rowe LD, Miller E, et al. Computed tomography in the maxillofacial trauma. Laryngoscope 1981;91:745-757. DOI: 10.1288/00005537198105000-00007.

4. Adenyemo WL, Akadiri OA. A systematic review of the diagnostic role of ultrasonography in maxillofacial fractures. Int J Oral Maxillofac Surg 2011;40(7):655-661. DOI: 10.1016/j.ijom.2011.02.001.

5. Banks $P$, Brown A. Etiology, surgical anatomy and classification. In: Banks P, Brown A. ed. Fractures of the facial skeleton, 1st ed. Philadelphia, USA: Elsevier, 2001.

6. Larry H, Hollier Jr, et al. MD Facial Trauma: General Principles of Management. J Craniofac Surg 2010;21:1051-1053. DOI: 10.1097/ SCS.0b013e3181e5701c.

7. Joshi N, Kira A, et al. Diagnostic accuracy of history, physical examination, and bedside ultrasound for diagnosis of extremity fractures in the emergency department: a systematic review. Acad Emerg Med 2013;20:1-15. DOI: 10.1111/acem.12058.

8. Kane D, Grassi W, et al. A brief history of musculoskeletal ultrasound: "From bats and ships to babies and hips". Rheumatology (oxford) 2004 Jul 1;43(7):931-933. DOI: 10.1093/rheumatology/keh004.

9. Hong HS, Cha JG, et al. High resolution sonography for nasal fracture in children. AJR Am J Roentgenol 2007;188(1):W8692. DOI: 10.2214/ AJR.05.1067.
10. Mohammadi A, Ghasemi-Rad M. Nasal bone fracture-ultrasonography or computed tomography? Med Ultrason 2011 Dec;13(4): 292-295.

11. Friedrich RE, Heiland $M$, et al. Potentials of ultrasound in the diagnosis of midfacial fractures. Clin Oral Investig 2003 Dec;7(4):226-229. DOI: 10.1007/s00784-003-0232-5.

12. Takashi $H$, Ernest $\mathrm{K}$, et al. Ultrasonic Observation of Facial Bone Fractures. J Oral Maxillofac Surg 1996;54:776-779. DOI: 10.1016/ S0278-2391(96)90703-X.

13. Singh KS, Jayachandran S. A comparative study on the diagnostic utility of ultrasonography with conventional radiography and computed tomography scan in detection of zygomatic arch and mandibular fractures. Contemp Clin Dent 2014 Apr;5(2):166-169. DOI: 10.4103/0976-237X.132306.

14. Kleinheinz J, Anastassov GE, et al. Ultrasonographic vs conventional diagnostic procedures in dislocated subcondylar mandibular fractures. J Craniomaxillofac Trauma 1997;3:40-42.

15. Blessmann $M$, Pohlenz $P$, et al. Validation of a new training tool for ultrasound as ad diagnostic modality in suspected midfacial fractures. Int J Oral Maxillofac Surg 2007;36(6):501-506. DOI: 10.1016/ j.ijom.2007.01.016. 